\title{
Investigating the Link Between Liking Versus Wanting Self-Esteem and Depression in a Nationally Representative Sample of Americon Adults
}

\author{
Brad J. Bushman, ${ }^{1}$ Scott J. Moeller, ${ }^{2}$ Sara Konrath, ${ }^{3}$ and \\ Jennifer Crocker ${ }^{4}$
}

'The Ohio State University and VU University, Amsterdorm, the Netherlonds

${ }^{2}$ Brookhaven National Laboratory

${ }^{3}$ University of Michigon

${ }^{4}$ The Ohio State University

\begin{abstract}
The self-esteem movement has been around since the 1970s, and may have influenced how much value people place on selfesteem. We predicted a negative relationship between age and the amount of value placed on self-esteem boosts. We also investigated the correlates of liking versus wanting self-esteem boosts (and other pleasant rewards) on depression. A nationally representative sample of American adults $(N=867)$ indicated how much they liked and wanted several pleasant rewards (i.e., sex, food, alcohol, money, friendship, self-esteem boost). They also completed a standardized measure of depressive symptoms. As expected, there was a negative relationship between age and valuing selfesteem boosts, sex, and alcohol. People with depressive symptoms wanted self-esteem boosts, even though they did not like them very much. Similar effects were obtained for depressive symptoms and alcohol and friendship. This is the first research to show that self-esteem boosts are more valued among a nationally representative sample of younger American adults. It also is the first research to explore the association between depression and the motivation to boost self-esteem. People with depressive symptoms want self-esteem, and may pursue it, but this pursuit may feel unrewarding because they do not derive pleasure from it.
\end{abstract}

Correspondence concerning this article should be addressed to Brad J. Bushman, School of Communication, The Ohio State University, 3127 Derby Hall, 154 North Oval Mall, Columbus, OH 43210-1339. Email: bushman.20@osu.edu.

Journal of Personality 80:5, October 2012

(C) 2012 The Authors

Journal of Personality (C) 2012, Wiley Periodicals, Inc.

DOI: $10.1111 / \mathrm{j} .1467-6494.2012 .00781 . \mathrm{x}$ 
A desire to be observed, considered, esteemed, praised, beloved, and admired by his fellows is one of the earliest as well as the keenest dispositions discovered in the heart of man.

—John Adams (1797-1801), 2nd U.S. President

This quote from one of America's founding fathers provides a succinct and accurate description of the very high value many Americans place on self-esteem, perhaps even more today than when Adams said it. Why do Americans place so much value on selfesteem? One reason is that self-esteem boosts such as praise and compliments make people feel good (e.g., Bani, 2011; Coatsworth \& Conroy, 2009). This is not surprising. What is surprising, however, is research showing that college students would rather receive a boost to their self-esteem than engage in their favorite sexual activity, eat their favorite food, drink their favorite alcoholic beverage, see their best friend, or receive a paycheck (Bushman, Moeller, \& Crocker, 2011). Self-esteem boosts trumped all these pleasant rewards in our previous research.

But do college students represent the U.S. population of adults when it comes to the value they place on self-esteem? We think not. Given the prominence of the self-esteem movement in American society, we predict a negative relationship between age and valuing self-esteem boosts in American adults. The self-esteem movement began in 1969 when psychotherapist Nathaniel Branden published his highly acclaimed book The Psychology of Self-Esteem. Boosting self-esteem was viewed as a panacea for all personal and social ills. As Branden put it, "I cannot think of a single psychological problem-from anxiety and depression, to fear of intimacy or of success, to spouse battery or child molestation - that is not traceable to the problem of low self-esteem" (Branden, 1984, p.12). Branden's ideas caught on quickly and soon became implemented in the American educational system (Stout, 2000). For example, in 1986, California Governor George Deukmejian signed into law a piece of legislation that created a self-esteem task force for the state's schools.

But is the United States really suffering from an epidemic of low self-esteem? Research suggests otherwise. In fact, average self-esteem scores have been rising in a linear fashion since the 1970s (Gentile, Twenge, \& Campbell, 2010; Twenge \& Campbell, 2002, 2008). Indeed, the term self-esteem in American books has become increasingly popular since the 1970 s compared to the term self-control 
(Konrath \& Anderson, 2012), highlighting America's obsession with the topic. If anything, self-esteem in the United States is unrealistically high. In one survey, 93\% of American drivers said they were above average in driving ability (Svenson, 1981). Statistically, one would expect only about $50 \%$ of drivers to be above average. In a large survey of a million American high school students (College Board, 1976-1977), only 2\% said they were below average in leadership ability (70\% said they were above average). Even more strikingly, not one in a million students claimed to be below average in the ability to get along with others, whereas $25 \%$ claimed to be in the top $1 \%$ ! This tendency to view oneself as better than average has been dubbed the "Lake Wobegon effect" (e.g., Carney, 1991), after Garrison Keillor's apocryphal town in Minnesota where "all the children are above average." Could the value placed on self-esteem be so high that younger Americans show a kind of addiction to it?

\section{Testing for One Sign of Self-Esteem Addiction: Wanting More Than Liking}

Typically, people both want and like pleasant rewards, but wanting and liking can be dissociated (T. E. Robinson \& Berridge, 2003). Wanting refers to how much effort people are willing to expend to obtain a particular reward. When people really want something, they try very hard to obtain it. Liking refers to how much people enjoy the reward, or the pleasure they derive from it. In the case of addiction, people often want the reward more than they like it. For example, drug-addicted individuals may really want a drug, even to the point of "needing" it, but once they get it, they may not find it particularly pleasurable. Drugs may sensitize brain regions involved in wanting but not liking rewards (T. E. Robinson \& Berridge, 2003). If people are "addicted" to self-esteem, one manifestation of this addiction could be that they may want it more than they like it.

To test for signs of possible addiction to self-esteem, college students in our previous research were asked how much they liked and wanted each reward (Bushman et al., 2011). Results showed that although college students liked all the rewards more than they wanted them, the difference between liking and wanting these rewards was lowest for self-esteem, which is one potential sign of addiction to self-esteem. In the present study, which used a representative sample 
of American adults, we also measured liking and wanting of the different rewards.

\section{The Link Between Wanting Versus Liking Self-Esteem and Depression}

Are symptoms of poor mental health associated with placing such high value on self-esteem? One of the most robust findings in the clinical literature is that depressed individuals have low self-esteem (e.g., Beck, 1972). It is therefore surprising that previous research has not investigated the link between valuing self-esteem boosts and depression. The present research investigates two components of valuing self-esteem boosts: liking and wanting.

A core symptom of major depressive disorder is anhedonia - the inability to feel pleasure from previously pleasurable activities (American Psychiatric Association, 2000). Prior research does not often distinguish between liking and wanting in depression, using anhedonia to mean deficits in both (e.g., Henriques \& Davidson, 2000; Rottenberg, Kasch, Gross, \& Gottlib, 2002). Our distinction between wanting and liking self-esteem is consistent with recent thinking about depression (Treadway \& Zald, 2011), which proposes that the concept of anhedonia be modified to include two components: deficits in pleasure and deficits in motivation. With regard to self-esteem boosts, deficits in pleasure would be related to low levels of liking self-esteem boosts, whereas deficits in motivation would be related to low levels of wanting self-esteem boosts.

However, research suggests that liking and wanting can be dissociated at times. Thus, we should not simply expect that people with depressive symptoms will have low levels of both liking (pleasure) and wanting (motivation) when it comes to self-esteem boosts. For example, in one nonclinical community sample (Waugh \& Gotlib, 2008), liking and wanting were related when it was easy to obtain a reward but were dissociated when it was difficult to obtain the same reward. In a clinical sample (Sherdell, Waugh, \& Gotlib, 2012), although depressed individuals liked rewards as much as nondepressed controls, they did not want them as much.

Based on the latter study, one might expect that the participants in our sample who score higher in depression might like self-esteem boosts but not really want them. However, several lines of research lead us to make the opposite prediction when the reward is selfesteem. Depression is associated with low self-esteem, instability of 
self-esteem (e.g., Roberts, Kassel, \& Gotlib, 1995), and contingent self-esteem (e.g., Sargent \& Crocker, 2006). Depressed people are highly motivated to validate their worth (Dykman, 1998) and seek reassurance that others value them (Joiner, Metalsky, Katz, \& Beach, 1999). These findings suggest that people who are depressed desperately crave self-esteem boosts but may have difficulty enjoying them because their chronic self-doubts and unstable, contingent selfesteem lead them to view such boosts as transient. Given that the distinction between liking and wanting rewards is relatively new within the depression literature, this study can examine which of these hypotheses has more support.

\section{METHOD}

\section{Participants}

Participants were 867 American adults 18 to 90 years old $\left(M_{\text {age }}=44.7\right.$, $S D=15.3 ; 63 \%$ female). The ethnic composition of the sample was $78.0 \%$ Caucasian, 6.9\% African American, 4.3\% Hispanic American, 2.4\% Asian American, and $8.4 \%$ Multiracial or Other. About 24\% of the sample had a college degree or higher. The median income range was $\$ 20,000$ to $\$ 39,000$. Participants were recruited by Qualtrics Panel, an online survey software company, and were paid $\$ 1$.

The survey was sent to a nationally representative sample of American adults. However, because some demographic groups had lower response rates than others, our sample deviated from national norms in some regards. Based on the U.S. Census Bureau's, Statistical Abstracts of the United States (2011), the national norms are $M_{\text {age }}=36.8 ; 51 \%$ female; 65.1\% Caucasian, 12.3\% African American, 15.8\% Hispanic American, 4.5\% Asian American, 2.3\% Multiracial or Other; 29.5\% college degree or higher; and $M_{\text {income }}=\$ 39,112$. Thus, our sample had more females, was older than average, and was slightly less diverse. We therefore weighted our sample for gender and race using U.S. Census Bureau statistics so that it matched national norms, as other researchers have done (e.g., Syed \& Juan, 2011).

\section{Procedure}

Participants first completed a modified version of the Sensitivity to Reinforcement of Addictive and Other Primary Rewards scale (Goldstein et al., 2010), which was originally designed to test preference for addictive drugs over other pleasant rewards. We modified the scale to test prefer- 
ence for self-esteem boosts over other pleasant rewards (Bushman et al., 2011). Participants were asked to think about eating their favorite food, drinking their favorite alcoholic beverage, performing their favorite sexual activity, receiving their paycheck (currently or in the past), seeing their best friend, and receiving their favorite self-esteem boost (e.g., praise). The scale focuses on the difference between wanting and liking pleasant rewards because individuals addicted to rewards may want them even though they do not particularly like them (T. E. Robinson \& Berridge, 2003). For each reward, they rated "how pleasant it was" (i.e., how much they liked it) and "how much they wanted it," in general $(1=$ not at all, $5=$ extremely). Rewards were presented in a random order.

When people have been deprived of a reward, they may value it even more. Thus, participants also reported how long it had been since they had each reward. All questions were asked in terms of days (e.g., "How many days has it been since you last drank your favorite alcoholic beverage?), except eating (i.e., "How many hours has it been since you last ate?") and receiving a paycheck (i.e., "How many weeks has it been since you received a paycheck?"). When these times were entered as continuous covariates in the analyses, they did not influence the results. Thus, we report the simpler results that exclude these covariates.

Next, participants completed the 20-item Center for Epidemiologic Studies Depression Scale (CES-D; Radloff, 1977; Cronbach $\alpha=.93$ ), which measures depressive symptoms such as sadness, loneliness, and feelings of worthlessness. The median depression score in the sample was 13.68, below the commonly used cut-off value of 16 that indicates the presence of depressive symptoms. Finally, participants answered demographic questions (i.e., gender, age, ethnicity, income, education).

\section{RESULTS}

\section{Data Analysis Strategy}

Table 1 contains the correlations among the variables in the study. Data were analyzed using a 6 (food, alcohol, sex, paycheck, friends, self-esteem) $\times 2$ (like, want) repeated measures analysis of variance (ANOVA). Following a significant main effect for type of reward, we compared each reward with self-esteem. We adopted this approach because we were primarily interested in comparing self-esteem with other rewards, as in our previous research (Bushman et al., 2011). Moreover, comparing all possible pairs of rewards would have required 21 pairwise comparisons, which greatly increases the likelihood of Type I errors. To correct for Type I errors, the Bonferroni 


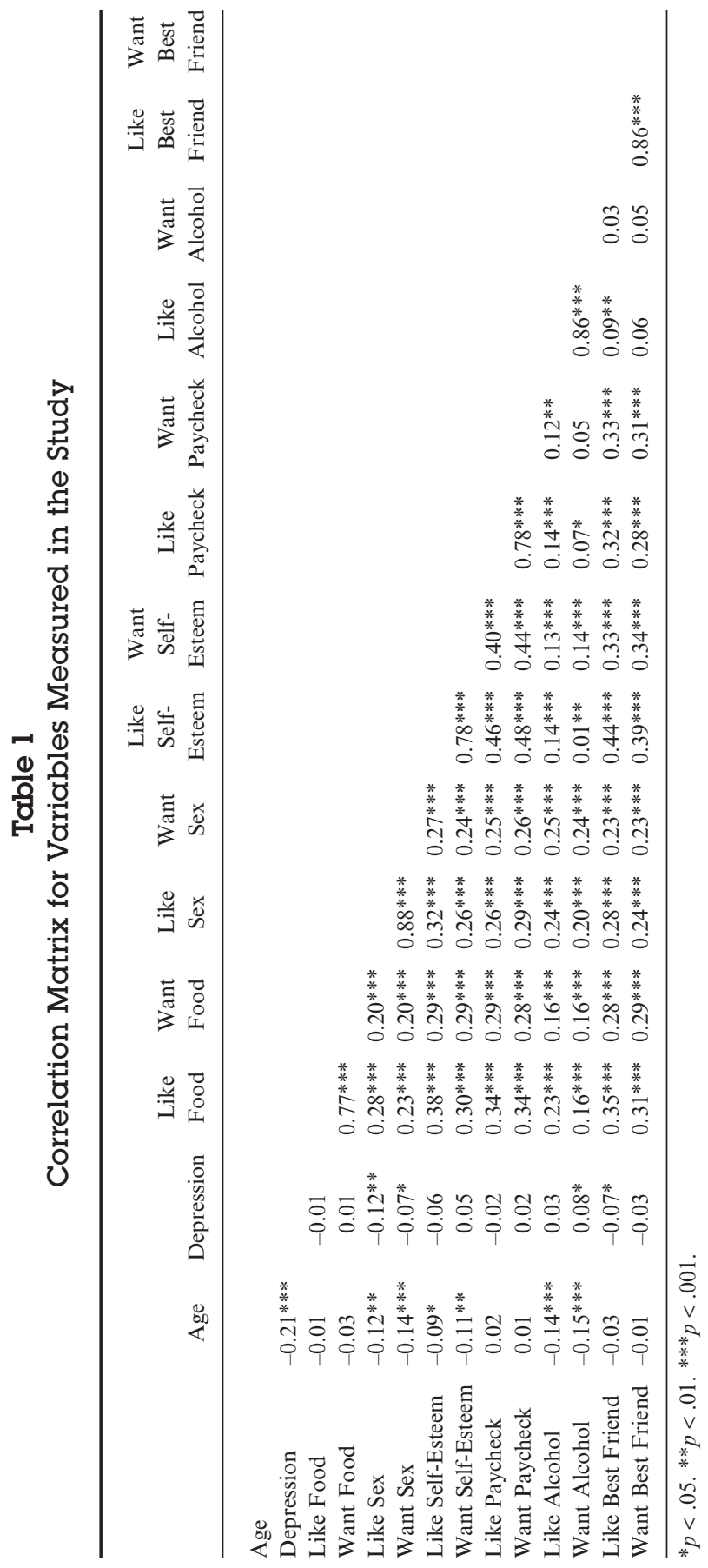


corrected significance level for these comparisons with self-esteem was .01 (i.e., $p<.05$ divided by five comparisons). Significant interactions were followed by paired $t$ tests or regressions, as appropriate. We then tested test-specific hypotheses of age and depression. We entered age and depression as continuous moderators in the model. All regression analyses were conducted with and without the sampling weights based on national statistics. Because applying these weights did not change any conclusions, we report only the more representative weighted results.

\section{Valuing of Rewards}

The $6 \times 2$ ANOVA showed a main effect for type of reward, $F(5$, $742)=164.75, p<.001$ (see Figure 1). Overall, participants valued (averaged across liking and wanting) their favorite self-esteem boost more than drinking their favorite alcoholic beverage $(p<.001$, $d=1.73)$ or engaging in their favorite sexual activity $(p<.001$, $d=0.64)$. Self-esteem did not differ from the other rewards $(p s>.2)$,

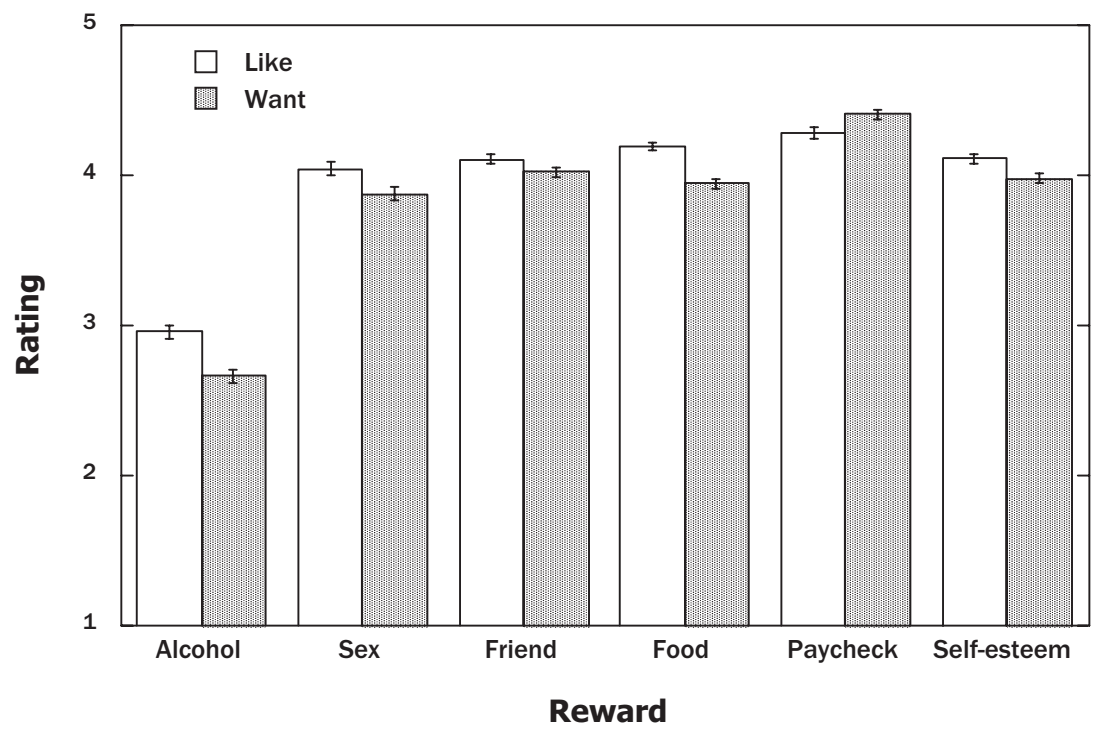

Figure 1

Liking and wanting scores for different rewards in a nationally representative sample of American adults. Capped vertical bars denote 1 SE. 
in contrast to our previous findings in which self-esteem also trumped these rewards (see Bushman et al., 2011). Participants also liked rewards more than they wanted them, $F(1,746)=141.43$, $p<.001, d=0.87$. These two main effects, however, were qualified by a significant interaction between type of reward and liking versus wanting, $F(5,742)=35.90, p<.001$. Follow-up tests showed that participants liked all rewards more than they wanted them $(F \mathrm{~s}>20.98, p \mathrm{~s}<.001, d \mathrm{~s}>0.33)$, with one exception-participants wanted to receive their paycheck more than they liked receiving it, $F(1,788)=34.66, p<.001, d=0.42$ (see Figure 1$)$.

\section{Moderation by Age}

We tested the hypothesis that age was negatively related to valuing self-esteem boosts. When age was entered as a continuous variable into the $6 \times 2$ ANOVA, it significantly moderated the main effect for type of reward, $F(5,706)=4.72, p<.001, d=0.36$. Follow-up regression analyses were conducted between age and valuing rewards (averaged across liking and wanting because the three-way interaction was not significant). As expected, age was negatively related to valuing self-esteem boosts $(\beta=-.08, p<.05)$. Age was also negatively related to valuing sex $(\beta=-.08, p<.05)$ and alcohol $(\beta=-.15$, $p<.001)$. The younger the participants in our sample were, the more they valued self-esteem, sex, and alcohol. Age was not significantly related to the other rewards $(-.03<\beta s<.03, p s>.47)$.

\section{Moderation by Depression}

We tested the hypothesis that depressed individuals fail to derive as much pleasure from pleasant rewards as others do, even though they might want them. We also tested whether this effect applied equally to all rewards, or whether it was unique to self-esteem. When depression was entered into the $6 \times 2$ ANOVA as a continuous moderator, there was a significant liking versus wanting $\times$ depression interaction, $F(1,738)=23.63, p<.001$.

Hierarchical regression analyses were used to explore this significant interaction. Liking and wanting were entered as predictors in Step 1, and their interaction was entered as a predictor in Step 2, with depression as the outcome variable (Aiken \& West, 1991). All predictors were centered. We first performed this analysis combined across all rewards (i.e., testing for an omnibus interaction effect), and 
the interaction term was significant $\left(\Delta R^{2}=.015, \beta=.13, t=3.47\right.$, $p<.01)$. To clarify this omnibus effect, we performed this analysis separately for each reward. Of greatest importance for our purposes, the interaction was significant for self-esteem $\left(\Delta R^{2}=.009, \beta=.11\right.$, $t=2.68, p<.01$ ), For self-esteem, simple slopes tests (computed $1 S D$ above and $1 S D$ below the mean of liking) indicated that wanting self-esteem more strongly predicted depression when liking selfesteem was high $(\beta=.31, p<.001)$ than when liking self-esteem was low $(\beta=.17, p<.01)$. As can be seen in Figure 2 , the lowest level of depression occurred for people who liked self-esteem but did not want it very badly - and it was lower than 16 , the value typically used to indicate the presence of depressive symptoms.

A similar interaction effect was obtained for alcohol $\left(\Delta R^{2}=.011\right.$, $\beta=.11, t=3.02, p<.01$ ). Simple slopes tests (computed $1 S D$ above and $1 S D$ below the mean of liking) indicated that wanting alcohol more strongly predicted depression when liking alcohol was high $(\beta=.37, p<.001)$ than when liking alcohol was low $(\beta=.12, p>.12)$. As can be seen in Figure 3, the lowest level of depression occurred for people who liked alcohol but did not want it very badly.

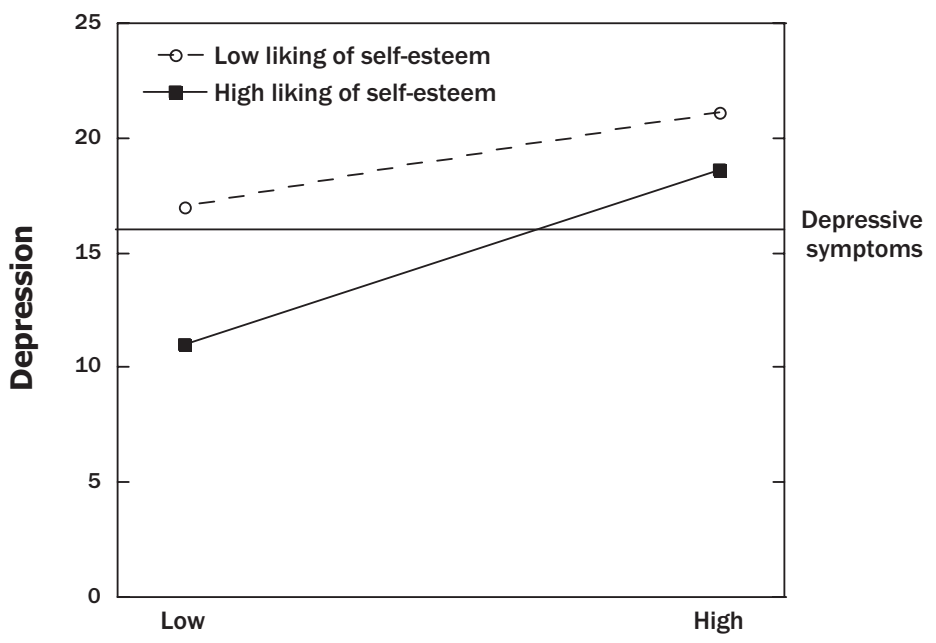

Want Self-esteem

Figure 2

Interactive effect of liking and wanting self-esteem on depression. Low scores are 1 SD below the mean, whereas high scores are $1 S D$ above the mean. 


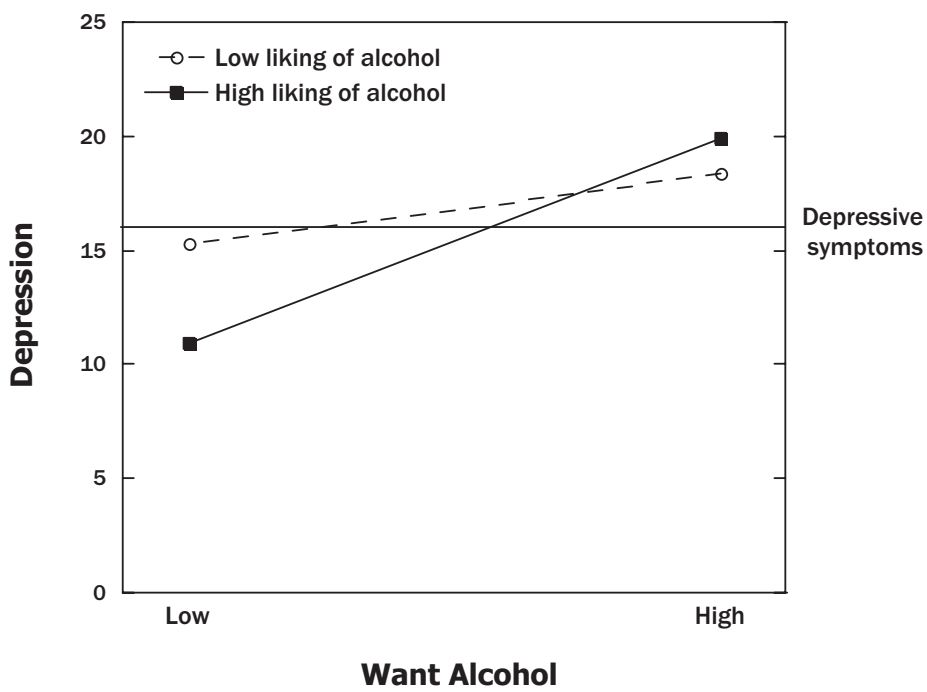

Figure 3

Interactive effect of liking and wanting alcohol on depression. Low scores are 1 SD below the mean, whereas high scores are $1 S D$ above the mean.

Likewise, a similar interaction effect was obtained for friendship $\left(\Delta R^{2}=.009, \beta=.11, t=2.64, p<.01\right)$. Simple slopes tests (computed $1 S D$ above and $1 S D$ below the mean of liking) indicated that wanting friendship more strongly predicted depression when liking friendship was high $(\beta=.30, p<.001)$ than when liking friendship was low $(\beta=.17, p<.005)$. As can be seen in Figure 4 , the lowest level of depression occurred for people who liked friendship but did not want it very badly.

\section{DISCUSSION}

Consistent with our previous research (Bushman et al., 2011), selfesteem trumped sex and alcohol in a representative sample of American adults. In contrast to our previous research, self-esteem did not trump food, money, and friendship. Perhaps the difference is due to the difficult economic times many Americans in our present sample were facing. Participants in our previous research were University of Michigan students from relatively wealthy fami- 


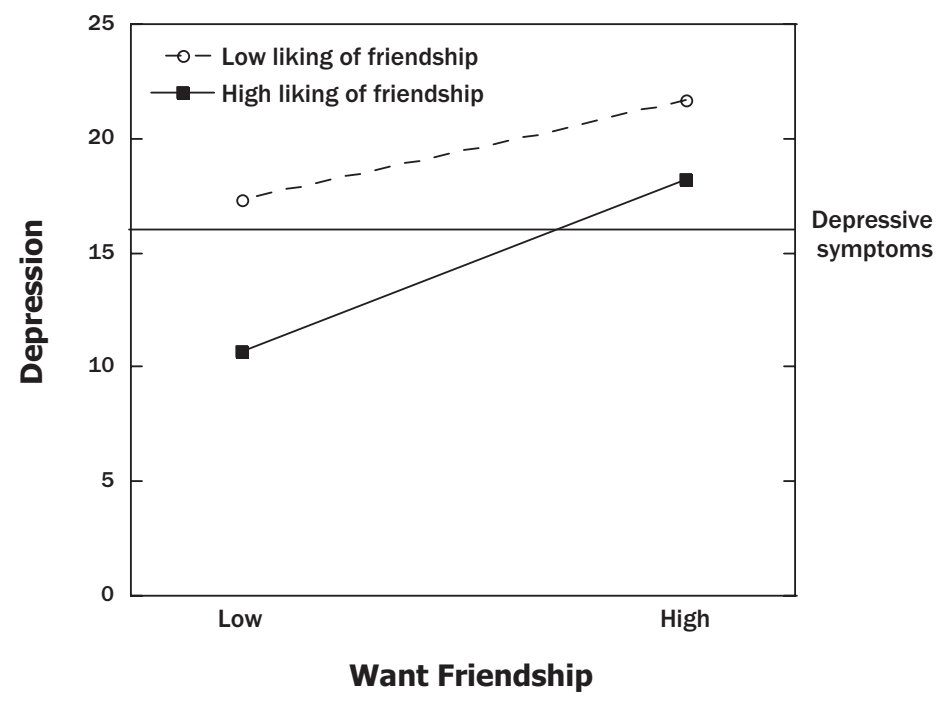

Figure 4

Interactive effect of liking and wanting friendship on depression. Low scores are $1 S D$ below the mean, whereas high scores are $1 S D$ above the mean.

lies. Previous research has shown higher levels of self-esteem among individuals from higher socioeconomic classes (e.g., Twenge \& Campbell, 2002).

In our previous research (Bushman et al., 2011), liking was higher than wanting for all rewards, but the difference was smallest for self-esteem. In the present research, liking was higher than wanting for all rewards but receiving a paycheck. Participants in the present sample really wanted money, even more than they liked it. Once again, this may be a sign of difficult financial times. Indeed, participants in the present study were willing to complete a 20 -minute survey for only $\$ 1$.

As expected, age was negatively related to valuing self-esteem boosts. Although these effects were small, and although we cannot tease apart cohort versus developmental effects with our crosssectional data, our results may reflect the fact that younger adults in our sample were heavily immersed in the self-esteem movement. Our results extend findings showing that self-esteem levels are increasing over time among young Americans (Twenge, 2006; Twenge \& Campbell, 2002, 2008); not only is self-esteem increasing overall, but it also 
seems to be especially valued by young Americans. Not surprisingly, age was also negatively related to valuing alcohol and sex. Because alcohol is illegal to consume for participants under 21 years old, younger participants may value it more because it is a "forbidden fruit."

Our findings also show that people who are depressed do not lack the motivation for self-esteem-they want it. In fact, wanting selfesteem is positively related to depression. Also, liking self-esteem, which is the pleasure aspect, moderates the association between wanting self-esteem and depression. Low levels of depression are linked to liking but not wanting self-esteem. In contrast, high levels of depression are associated with wanting, but not liking, self-esteem. These findings extend current thinking in the field. Of the two competing hypotheses raised in the introduction about the relationship between liking and wanting self-esteem and depression, our results support the view that although people with depressive symptoms may have difficulty enjoying self-esteem boosts, they nonetheless appear to want them.

These findings further underscore the importance of the liking versus wanting distinction. The present research suggests that liking and wanting should be dissociated, rather than lumped together into the single concept of anhedonia. Accordingly, our findings are consistent with recent theories that have emphasized the importance of distinguishing between deficits in pleasure and deficits in motivation in depressed individuals (Treadway \& Zald, 2011). The deficits in pleasure are indicated by how much individuals like self-esteem boosts, whereas the deficits in motivation are indicated by how much individuals want self-esteem boosts. To our knowledge, this is the first research to explore the association between depression and the motivation to boost self-esteem, and to distinguish between the liking and wanting components of valuing self-esteem. People with depressive symptoms want self-esteem, and they may pursue it, but this pursuit may feel unrewarding because they do not derive pleasure from it. In other words, for people who have more depressive symptoms, there are signs of addiction to self-esteem. This distinction between liking and wanting rewards and depression is unique to self-esteem, alcohol, and friendship but not other pleasant rewards (i.e., food, sex, money).

The fact that similar results were found for alcohol is not surprising because previous research has shown a strong relation between 
alcohol use and depression (e.g., Fergusson, Boden, \& Horwood, 2009). However, this interaction effect shows that wanting alcohol may be more strongly linked to depression than liking alcohol. Because wanting alcohol is more likely associated with alcohol dependence than liking alcohol, these findings are consistent with a classical theory of alcohol dependence (and drug dependence more generally) called self-medication or negative reinforcement (e.g., J. Robinson, Sareen, Cox, \& Bolton, 2009; Tomlinson, Tate, Anderson, McCarthy, \& Brown, 2006), which suggests that people often drink to quell negative affect.

Numerous studies have shown that having friends, especially close friends, is negatively related to depressive symptoms (e.g., Cambron \& Citelli, 2010; Patterson \& Bettini, 1993; Potts, 1997). Indeed, seeing a best friend may be one way to boost self-esteem. In the present study, the pleasure obtained from a self-esteem boost and seeing a best friend were correlated $r=.44(p<.0001)$, whereas wanting a self-esteem boost and wanting to see a best friend were correlated $r=.34(p<.0001)$. Neither self-esteem nor seeing a best friend were strongly correlated with liking or wanting alcohol ( $r \mathrm{~s}<.14)$; indeed, the smallest correlation between self-esteem and friends ( $r=.33$, between liking friends and wanting self-esteem) was significantly higher than the highest correlation between alcohol and self-esteem or friends $(r=.14$, between wanting alcohol and wanting self-esteem; $z=4.12, p<.001)$.

\section{Limitations and Future Research}

The present study focused on the link between placing high value on self-esteem boosts and depression. Future research will need to extend these results to people with clinically diagnosed depression. In addition, if wanting self-esteem is related to depression, it may be indirectly related to potentially self-destructive behaviors people engage in to quell negative affect, such as drinking alcohol or taking drugs (e.g., Heilig, Egli, Crabbe, \& Becker, 2009).

Future research can also explore other aspects of self-esteem wanting, such as its interference with relationships or professional competence, two domains in which individuals often expend considerable effort to obtain self-esteem boosts.

Future research can also focus on the link between depression and liking versus wanting self-esteem boosts that are either easy versus 
difficult to obtain. Previous research using a nonclinical sample has shown that the more effortful a reward is to obtain, the greater the dissociation between liking and wanting the reward (Waugh \& Gotlib, 2008). Thus, the dissociation between liking and wanting that occurs in our study might be explained by the difficulty that depressed people may have in obtaining self-esteem (and possibly close, meaningful friendships).

\section{CONCLUSION}

Self-esteem is a valuable commodity today, especially among younger adults. In our nationally representative sample of American adults, the younger the participants were, the more they valued self-esteem boosts. Depressed people also showed some signs of addiction to self-esteem. They wanted self-esteem as much as nondepressed people, but they did not like it as much. John Adams was seemingly correct in noting that people crave to be "observed, considered, esteemed, praised, beloved, and admired" by others. However, this craving for self-esteem boosts may be a signal for mental health problems. Although self-esteem boosts feel good, excessively wanting self-esteem may be linked to poor mental health.

\section{REFERENCES}

Aiken, L. S., \& West, S. G. (1991). Multiple regression: Testing and interpreting interactions. Newbury Park, CA: Sage.

American Psychiatric Association. (2000). Diagnostic and statistical manual of mental health disorders (4th ed., text rev.). Washington, DC: Author.

Bani, M. (2011). The use and frequency of verbal and non-verbal praise in nurture groups. Emotional and Behavioural Difficulties, 16, 47-67.

Beck, A. T. (1972). Depression: Causes and treatment. Philadelphia: University of Pennsylvania Press.

Beck, T., \& Steer, A. (1987). Beck Depression Inventory manual. San Antonio, TX: Psychological Corporation.

Branden, N. (1969). The psychology of self-esteem. New York: Bantam.

Branden, N. (1984, August-September). In defense of self. Association for Humanistic Psychology, 12-13.

Bushman, B. J., Moeller, S. J., \& Crocker, J. (2011). Sweets, sex, or self-esteem? Comparing the value of self-esteem boosts with other pleasant rewards. Journal of Personality, 79, 993-1012. 
Cambron, M., \& Citelli, L. K. (2010). Examining the link between friendship contingent self-esteem and the self-propagating cycle of depression. Journal of Social and Clinical Psychology, 29, 701-726.

Carney, R. N. (1991). The "Lake Wobegon effect": Implications for the assessment of exceptional children. Journal of School Psychology, 29, 183-186.

Coatsworth, J. D., \& Conroy, D. E. (2009). The effects of autonomy-supportive coaching, need satisfaction, and self-perceptions on initiative and identity in youth swimmers. Developmental Psychology, 45, 320-328.

College Board. (1976-1977). Student Descriptive Questionnaire. Princeton, NJ: Educational Testing Service.

Dykman, B. M. (1998). Integrating cognitive and motivational factors in depression: Initial tests of a goal-orientation approach. Journal of Personality and Social Psychology, 74, 139-158.

Fergusson, D. M., Boden, J. M., \& Horwood, L. J. (2009). Tests of causal links between alcohol abuse or dependence and major depression. Archives of General Psychiatry, 66, 260-266.

Gentile, B., Twenge, J. M., \& Campbell, W. K. (2010). Birth cohort differences in self-esteem, 1988-2008: A cross-temporal meta-analysis. Review of General Psychology, 14, 261-268.

Goldstein, R. Z., Woicik, P. A., Moeller, S. J., Telang, F., Jayne, M., Wong, C., et al. (2010). Liking and wanting of drug and non-drug rewards in active cocaine users: The STRAP-R Questionnaire. Journal of Psychopharmacology, 24, 257-266.

Heilig, M., Egli, M., Crabbe, J. C., \& Becker, H. C. (2009). Acute withdrawal, protracted abstinence and negative affect in alcoholism: Are they linked? Addiction Biology, 15, 169-184.

Henriques, J. B., \& Davidson, R. J. (2000). Decreased responsiveness to reward in depression. Cognition and Emotion, 14, 711-724.

Joiner, T. E., Jr., Metalsky, G. I., Katz, J., \& Beach, S. R. H. (1999). Depression and excessive reassurance-seeking. Psychological Inquiry, 10, 269-278.

Konrath, S., \& Anderson, P. (2012). A century of self-esteem. In S. De Wals \& K. Meszaros (Eds.), Handbook on psychology of self-esteem (pp. 157-174). Hauppauge, NY: Nova Science.

Patterson, B. R., \& Bettini, L. M. (1993). Age, depression, and friendship: Development of a general friendship inventory. Communication Research Reports, 10, $161-170$.

Potts, M. K. (1997). Social support and depression among older adults living alone: The importance of friends within and outside of a retirement community. Social Work, 42, 348-362.

Radloff, L. S. (1977). The CES-D Scale: A self-report depression scale for research in the general population. Applied Psychological Measurement, 1(3), 385-401.

Roberts, J. E., Kassel, J. D., \& Gotlib, I. H. (1995). Level and stability of selfesteem as predictors of depressive symptoms. Personality and Individual Differences, 19, 217-224.

Robinson, J., Sareen, J., Cox, B. J., \& Bolton, J. (2009). Self-medication of anxiety disorders with alcohol and drugs: Results from a nationally representative sample. Journal of Anxiety Disorders, 23, 38-45. 
Robinson, T. E., \& Berridge, K. C. (2003). Addiction. Annual Review of Psychology, 54, 25-53.

Rottenberg, J., Kasch, K. L., Gross, J. J., \& Gotlib, I. H. (2002). Sadness and amusement reactivity differentially predict concurrent and prospective functioning in major depressive disorder. Emotion, 2, 135-146.

Sargent, J., \& Crocker, J. (2006). Contingencies of self-worth and symptoms of depression in college students. Journal of Social and Clinical Psychology, 25, 628-646.

Sherdell, L., Waugh, C. E., \& Gotlib, I. H. (2012). Anticipatory pleasure predicts motivation for reward in major depression. Journal of Abnormal Psychology, 121, 51-60.

Stout, M. (2000). The feel-good curriculum: The dumbing down of America's kids in the name of self-esteem. New York: Perseus Books.

Svenson, O. (1981). Are we all less risky and more skillful than our fellow drivers? Acta Psychologia, 47(2), 143-148.

Syed, M., \& Juan, M. J. D. (2011). Discrimination and psychological distress: Examining the moderating role of social context in a nationally representative sample of Asian American adults. Asian American Journal of Psychology, 3, 104-120.

Tomlinson, K. L., Tate, S. T., Anderson, K. G., McCarthy, D. M., \& Brown, S. A. (2006). An examination of self-medication and rebound effects: Psychiatric symptomatology before and after alcohol or drug relapse. Addictive Behaviors, 31, 461-474

Treadway, M. T., \& Zald, D. H. (2011). Reconsidering anhedonia in depression: Lessons from translational neuroscience. Neuroscience and Biobehavioral Reviews, 35, 537-555.

Twenge, J. M. (2006). Generation Me: Why today's young Americans are more confident, assertive, entitled-And more miserable than ever before. New York: Free Press.

Twenge, J. M., \& Campbell, W. K. (2002). Self-esteem and socioeconomic status: A meta-analytic review. Personality and Social Psychology Review, 6, 59-71.

Twenge, J. M., \& Campbell, S. M. (2008). Generational differences in psychological traits and their impact on the workplace. Journal of Managerial Psychology, 23, 862-877.

U.S. Census Bureau. (2011). Statistical abstract of the United States: 2011 (130th ed.). Washington, DC: Author. Retrieved from http://www.census.gov/ compendia/statab/

Waugh, C. E., \& Gotlib, I. H. (2008). Motivation for reward as a function of required effort: Dissociating the "liking" from the "wanting" system in humans. Motivation and Emotion, 32, 323-330. 